\title{
Novel cis-restricted $\beta$-lactam combretastatin A-4 analogues display anti-vascular and anti-metastatic properties in vitro
}

\author{
SEEMA-MARIA NATHWANI ${ }^{1}$, LINDA HUGHES ${ }^{2}$, LISA M. GREENE ${ }^{1}$, MIRIAM CARR $^{3}$, \\ NIAMH M. O'BOYLE ${ }^{3}$, SUSAN McDONNELL ${ }^{2}$, MARY J. MEEGAN ${ }^{3}$ and DANIELA M. ZISTERER ${ }^{1}$ \\ ${ }^{1}$ School of Biochemistry and Immunology, Trinity Biomedical Sciences Institute, Trinity College Dublin, Dublin 2; \\ ${ }^{2}$ UCD School of Chemical and Bioprocess Engineering, University College Dublin, Belfield, Dublin 4; ${ }^{3}$ School of \\ Pharmacy and Pharmaceutical Sciences, Trinity Biomedical Sciences Institute, Trinity College Dublin, Dublin 2, Ireland
}

Received September 21, 2012; Accepted October 24, 2012

DOI: $10.3892 /$ or.2012.2181

\begin{abstract}
Combretastatin A-4 (CA-4) is a naturally occurring microtubular-destabilising agent that possesses potent anti-tumour and anti-vascular properties both in vitro and in vivo. Clinical trials to date indicate that its water-soluble prodrug, combretastatin A-4 phosphate (CA-4P), is well tolerated at therapeutically useful doses. However, the stilbenoid structure of CA-4, consisting of two phenyl rings linked by an ethylene bridge, renders the compound readily susceptible to isomerisation from its biologically active cis-conformation to its more thermodynamically stable but inactive trans-isomer. To circumvent this problem, we synthesised a series of $\mathrm{cis}$ restricted CA-4 analogues. Replacement of the ethylene bridge with a 1,4-diaryl-2-azetidinone ( $\beta$-lactam) ring provided a rigid scaffold thus preventing cis-trans isomerisation. We previously documented that these tubulin-depolymerising $\beta$-lactam compounds potently induced cell cycle arrest and apoptosis in a variety of cancerous cell lines (including those displaying multidrug resistance) and ex vivo patient samples, whilst exerting only minimal toxicity to normal cells. The purpose of this study was to elucidate the effect of the $\beta$-lactam compounds on both tumour vascularisation and tumour cell migration, two critical elements that occur during the growth and metastatic progression of tumours. We established that two representative $\beta$-lactam compounds, CA-104 and CA-432, exerted both anti-endothelial effects $\left[\mathrm{G}_{2} / \mathrm{M}\right.$ arrest and apoptosis of primary human umbilical vein endothelial cells (HUVECs)] and anti-angiogenic effects [inhibition of HUVEC migration and differentiation and reduced vascular endothelial growth factor (VEGF) release from MDA-MB-231 breast adenocarcinoma cells]. In addition, we established that lead analogue, CA-432, abrogated the migration of MDA-MB-231 cells indicating an
\end{abstract}

Correspondence to: Dr Seema M. Nathwani, School of Biochemistry and Immunology, Trinity Biomedical Sciences Institute, Trinity College Dublin, Dublin 2, Ireland

E-mail: nathwans@tcd.ie

Key words: combretastatin A-4, microtubule-targeting agents, endothelial cells, anti-vascular, metastasis anti-metastatic function for these compounds. In summary, our results to date collectively indicate that these $c i s$-restricted $\beta$-lactam CA-4 analogues may prove to be useful alternatives to CA-4 in the treatment of cancer but with the added advantage of improved stability of the cis-isomer.

\section{Introduction}

The combretastatins are a family of stilbenoids, some of which possess potent anti-tumour and anti-vascular properties. Originally isolated from the bark of the South African bush willow tree Combretum caffrum, these naturally occurring stilbenes consist of two phenyl rings, the A-ring and B-ring, linked by an ethylene bridge (1). The most extensively studied member of the family, combretastatin A-4 (CA-4) is well documented to function as a microtubule targeting agent (2). Microtubules are dynamic filaments composed of $\alpha$ - and $\beta$-tubulin heterodimers that are key components of the mitotic spindle. Thus, agents that interfere with microtubule dynamics perturb mitotic cell division (3). CA-4 is a tubulin depolymerising agent that interacts with $\beta$-tubulin at or close to its colchicine binding site leading to the destabilisation of microtubules and preventing the formation of the mitotic spindle and hence results in mitotic arrest and subsequently cell death of tumour cells $(2,4,5)$. Its water-soluble phosphate prodrug combretastatin A-4 phosphate (CA-4P) or fosbretabulin is readily cleaved in vivo by non-specific endogenous phosphatases to yield active CA-4 (6).

CA-4P induced rapid selective tumour vascular shutdown and tumour regression in both subcutaneous and orthotopical mouse tumour models at concentrations well below the maximum tolerated dose $(7,8)$. It also reduced tumour blood flow in phase I clinical trials at well tolerated doses $(9,10)$. Consequently, CA-4P has recently completed numerous phase II clinical trials including trials for the use of CA-4P in the treatment of advanced anaplastic thyroid cancer (11), CA-4P in combination with paclitaxel and/or carboplatin in the treatment of advanced solid tumours and combinations of CA-4P, anti-angiogenic bevacizumab, carboplatin and paclitaxel for chemotherapy naive non-small cell lung cancer (12). In addition, phase II trials for the treatment of neovascular age-related macular degeneration and polypoidal choroidal vasculopathy 
have also been undertaken (12). CA-4P in combination with bevacizumab is currently recruiting for phase II trials for reoccurring or persistent tumours of the ovarian epithelial, fallopian tube or peritoneal cavity and is about to enter phase I trials for the treatment of recurrent high grade gliomas (12).

While in vitro studies have demonstrated the anti-proliferative and cytotoxic effects of CA-4 on endothelial cells $(7,13)$, the rapid vascular changes observed in vivo occur too early to be attributed to endothelial cell death. The rapid response of endothelial cells to CA-4 is thought to involve disruption to interphase microtubules triggering rapid remodelling of the actin cytoskeleton, assembly of actin stress fibres, actinomyosin contractility, formation of focal adhesions and disruption of cell-cell junctions (14).

Both the success and the limitations of CA-4 lie in its stilbene structure, illustrated in Fig. 1. Only the cis-configuration of CA-4 is biologically active (15). The spatial arrangement between its 3,4,5-trimethyloxyphenyl A-ring and 3-hydroxy4-methoxyphenyl B-ring are crucial to its functionality and ability to interact with tubulin (15-17). However, the cis-isomer is intrinsically unstable and readily isomerises to the more thermodynamically stable but inactive trans-configuration (15). Cis-trans isomerisation can be triggered by heat, light and protic media thus lowering the therapeutic efficacy of the agent.

We recently synthesised a series of CA-4 analogues that have been stabilised in their cis-configuration by the replacement of the usual ethylene bridge of CA-4 with a 1,4 -diaryl-2-azetidinone $(\beta$-lactam) ring $(18,19)$. The $\beta$-lactam ring provided a scaffold structure that retained a similar spatial arrangement between the two phenyl rings as the cis-conformation of CA-4. These compounds were either unsubstituted at position $\mathrm{C}-3$ of the $\beta$-lactam ring or substituted with methyl groups (18) or aryl rings (19). Molecular docking studies indicated that representative compounds were capable of interacting with tubulin with similar positioning to CA-4. Several compounds inhibited tubulin polymerisation in vitro and demonstrated potent anti-mitotic potential in a selection of tumour cell lines derived of diverse origin including leukaemia, breast, non-small cell lung, colon, CNS, melanoma, ovarian, cervical, renal and prostate cancers (18-21).

Furthermore, low nanomolar concentrations of representative compounds caused tubulin depolymerisation, resulting in loss of cell viability mediated by $\mathrm{G}_{2} \mathrm{M}$ arrest and apoptosis of breast carcinoma ER-positive MCF-7 and ER-negative MDA-MB-231 cells whilst exerting no significant cytotoxicity to normal murine breast epithelial cells $\left(\mathrm{IC}_{50}>10 \mathrm{mM}\right)(19)$. Significantly, lead compound CA-432 also induced potent anti-tubulin, anti-proliferative and anti-mitotic effects in human promyelocytic leukaemia HL60 cells expressing multidrug-resistant transporters P-glycoprotein or breast cancer resistance protein (BCRP) and in ovarian carcinoma A2780 cells also expressing P-glycoprotein. Molecular docking studies supported the notion that CA-432 was not a substrate for P-glycoprotein. Furthermore, CA-432 induced apoptosis in ex vivo samples from chronic myeloid leukaemia (CML) patients including those displaying resistance to imatinib mesylate, the frontline treatment for CML (20).

While our studies to date demonstrate the cytotoxic effects of these cis-restricted $\beta$-lactam CA-4 analogues on a variety of tumour cells derived from both the haematopoietic system and from solid tumours, we have not investigated their effects on endothelial cells. Tumour vascularisation is essential for tumour growth and metastases. Therefore, the purpose of this study was to examine the anti-vascular, anti-angiogenic and anti-metastatic properties of these compounds through a series of in vitro tests. We selected two lead analogues, CA-104 and CA-432, for this purpose (Fig. 1). CA-104 was unsubstituted at position C-3 of the $\beta$-lactam ring (18), while, CA-432 was substituted with a 4-(3-hydroxy-4-methoxyaryl ring) (19). We established that both compounds displayed anti-endothelial properties in vitro. They induced tubulin depolymerisation in primary human umbilical vein endothelial cells (HUVECs). This effect was associated with a loss in endothelial cell viability mediated by $\mathrm{G}_{2} \mathrm{M}$ arrest and apoptosis. We also demonstrated both direct and indirect anti-angiogenic events. Both compounds prevented migration and in vitro capillary tubule formation by HUVECs whilst lead compound, CA-432, reduced the release of VEGF from breast adenocarcinoma MDA-MB-231 cells. Finally, we established that CA-432 abrogated migration of these highly metastatic MDA-MB-231 cells. Of note, these anti-angiogenic and anti-metastatic events preceded any cytotoxic effects attributed to the $\beta$-lactam analogues.

These findings indicate a novel function for these $\beta$-lactam CA-4 analogues. Our findings collectively demonstrated that these rigid $c i s$-restricted analogues exhibited anti-tumour, anti-vascular, anti-angiogenic and anti-metastatic properties with minimal toxicity to normal cells. Replacement of the ethylene bridge with a $\beta$-lactam ring yielded compounds that retained the in vitro functionality of CA-4 but with the additional advantage of conformational stability.

\section{Materials and methods}

Unless otherwise stated, chemicals were obtained from Sigma-Aldrich (Poole, Dorset, UK) and tissue culture vessels were sourced from Greiner Bio-One GmbH (Frickenhausen, Germany).

Cell culture. Pooled primary human umbilical vein endothelial cells (HUVECs) and their associated reagents were all obtained from Cascade Biologics (Invitrogen, Carlsbad, CA, USA). HUVECs were maintained between passages 1-4 in Medium 200 supplemented with LSGS (low serum growth factor supplement) and utilised for experiments at passage 4 . Human breast adenocarcinoma MDA-MB-231 cells (ATCC, Manassas, VA, USA) were maintained in Dulbecco's modified Eagle's medium (DMEM) enhanced with GlutaMAX-I and supplemented with $10 \%$ foetal bovine serum, $50 \mathrm{U} / \mathrm{ml}$ penicillin and $50 \mu \mathrm{g} / \mathrm{ml}$ streptomycin (all purchased from Gibco, Invitrogen). Cells were maintained in a humidified incubator at $37^{\circ} \mathrm{C}$ in $5 \% \mathrm{CO}_{2}$ and were subcultured by trypsinisation upon reaching $70-80 \%$ confluency.

Reagents. Two representative cis-restricted $\beta$-lactam combretastatin A-4 analogues were used in this study. Their structures are illustrated in Fig. 1. Analogue 4-(3-hydroxy4-methoxyphenyl)-1-(3,4,5-trimethoxyphenyl)azetidin-2-one (CA-104) was synthesised as previously described in Carr et al (18) where this compound was referred to as compound $12 \mathrm{~d}$. 
<smiles>COc1ccc(/C=C/c2ccc(OC)c(/C=C/c3cc(O)c(OC)c(OC)c3)c2)cc1O</smiles>

CA-104

CA-432
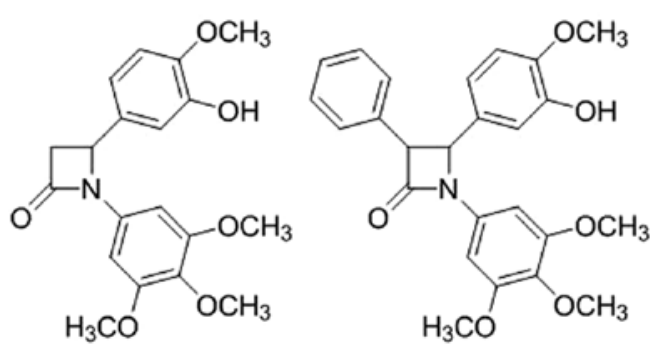

Figure 1. Chemical structures of combretastatin A-4 and its novel cis-restricted $\beta$-lactam analogues, CA-104 and CA-432.

Analogue 4-(3-hydroxy-4-methoxyphenyl)-3-phenyl-1(3,4,5-trimethoxyphenyl)azetidin-2-one (CA-432) was synthesised as described in O'Boyle et al (19) where it was referred to as compound 35 . The analogues were dissolved in ethanol and stored in the dark at $-20^{\circ} \mathrm{C}$. Human recombinant VEGF165 (R\&D Systems Inc., Minneapolis, MN, USA) was reconstituted to $1 \mu \mathrm{g} / \mathrm{ml}$ in $0.1 \%(\mathrm{w} / \mathrm{v})$ bovine serum albumin (BSA) and also stored at $-20^{\circ} \mathrm{C}$.

Cell viability assays. HUVECs (20,000 cells/well) or MDA-MB-231 cells (12,000 cells/well) were grown on 96 -well plates. The cells were treated ( $24 \mathrm{~h}$ post-seeding) with a range of concentrations of the analogues for up to $72 \mathrm{~h}$. Cellular metabolic activity and hence cell viability was monitored using AlamarBlue ${ }^{\mathrm{TM}}$ dye (BioSource, Invitrogen) which was added to each well [final concentration of $10 \%$ $(\mathrm{v} / \mathrm{v})]$ and incubated at $37^{\circ} \mathrm{C}$. The change from an oxidized indigo blue non-fluorescent state to a fluorescent pink state in the reduced environment of living cells was measured at an excitation wavelength of $544 \mathrm{~nm}$ and an emission wavelength of $590 \mathrm{~nm}$ using a SpectraMax Gemini spectrofluorometric microtiter well plate reader (Molecular Devices, Sunnyvale, CA, USA). The results were expressed as the percentage of cell viability relative to the vehicle-treated control cells (100\%). Dose-response curves were plotted, and $\mathrm{IC}_{50}$ values (the concentration of compound resulting in $50 \%$ reduction in cell viability) were obtained using Prism GraphPad 4.

Determination of DNA content. Following treatment, HUVECs were harvested by centrifugation at $800 \mathrm{x} \mathrm{g}$ for $10 \mathrm{~min}$. Cell pellets were resuspended in $200 \mu \mathrm{l}$ PBS and fixed by a drop-wise addition of $2 \mathrm{ml}$ of ice-cold $70 \%$ (v/v) ethanol/ PBS while gently vortexing. Following overnight fixation at $-20^{\circ} \mathrm{C}$ the cells were again centrifuged to remove the ethanol and resuspended in PBS supplemented with $0.5 \mathrm{mg} / \mathrm{ml}$ RNase
A and $0.15 \mathrm{mg} / \mathrm{ml}$ propidium iodide. Cells were incubated in the dark at $37^{\circ} \mathrm{C}$ for $30 \mathrm{~min}$. The fluorescence emitted from the propidium iodide was measured on a linear scale using a FACSCalibur flow cytometer (Becton Dickinson, San Jose, CA, USA). Data collections (10,000 events per sample) were gated to exclude cell debris and cell aggregates. Fluorescence was proportional to the amount of DNA present in each entity and therefore indicated the stage of the cell cycle it was in. Cells in $G_{0} / G_{1}$ were diploid (2N DNA content), cells in $G_{2} / M$ were tetraploid (4N DNA content), cells in the $\mathrm{S}$ phase had DNA contents between $2 \mathrm{~N}$ and $4 \mathrm{~N}$, while apoptotic cells were hypoploid and contained $<2 \mathrm{~N}$ DNA. All data were recorded and analysed using the CellQuest software (Becton Dickinson).

Microtubule staining. HUVECs $(60,000$ cells/chamber $)$ were cultured on BD Falcon ${ }^{\mathrm{TM}}$ 4-chamber glass slides (BD Biosciences, Bedford, MA, USA) for $24 \mathrm{~h}$. Following treatment for $16 \mathrm{~h}$, the cells were fixed in $100 \%$ methanol at $-20^{\circ} \mathrm{C}$ and the microtubular network was detected by indirect immunofluorescence as previously described (22). Briefly, the slides were sequentially incubated in a blocking solution $[5 \%(\mathrm{w} / \mathrm{v})$ BSA/0.1\% (v/v) Triton X-100/PBS], monoclonal anti- $\alpha$-tubulin antibodies (Merck Biosciences, Nottingham, UK), fluorescein isothiocyanate (FITC)-conjugated rabbit anti-mouse antibodies (DakoCytomation, Glostrup, Denmark) and finally $0.2 \mu \mathrm{g} / \mathrm{ml}$ propidium iodide (to stain DNA). An anti-quenching solution ( $2 \mu \mathrm{g} / \mathrm{ml} p$-phenylenediamine in 50:50 glycerol:PBS) was applied to the surface of the slides and coverslips were mounted. The organisation of the microtubule network (green) and the cellular DNA (red) was visualised under a x60 oil-immersion lens using an Olympus IX81 fluorescent microscope (Olympus Corporation, Tokyo, Japan).

Endothelial cell migration. Costar ${ }^{\circledR} 8 \mu \mathrm{M}$-pore Transwell inserts (Corning Incorporated, Corning, NY, USA) were coated overnight at $4^{\circ} \mathrm{C}$ with $10 \mu \mathrm{g} / \mathrm{ml}$ human fibronectin. HUVECs (10,000 cells in $100 \mu \mathrm{l}$ medium) were seeded onto the transwell inserts, placed in 24-well plates containing $0.6 \mathrm{ml}$ medium and incubated for $1 \mathrm{~h}$. HUVEC migration was stimulated by addition of $10 \mathrm{ng} / \mathrm{ml}$ VEGF to the lower well. Vehicle or the indicated analogues were also added to the lower wells. After a period of $6 \mathrm{~h}$ the upper surfaces of the inserts were swabbed to remove non-migrated cells. Filters were incubated overnight in a solution containing $0.5 \%$ toluidine blue $\mathrm{O}$ and $0.5 \%$ sodium tetraborate to stain the migrated cells. Following solubilisation of the cells using $0.2 \%$ (w/v) SDS in $20 \mathrm{mM}$ Tris- $\mathrm{HCl}, \mathrm{pH} 7.7$, the absorbance was determined at $650 \mathrm{~nm}$ in a spectrophotometer (Molecular Devices).

In vitro tubule formation. HUVECs $\left(1.5 \times 10^{6}\right.$ cells/well), were incubated on BD Biocoat $^{\mathrm{TM}}$ Matrigel $^{\mathrm{TM}}$-coated 6-well plates (BD Biosciences) for $6 \mathrm{~h}$ in the presence of vehicle or the indicated compounds. The ability of the HUVECs to spontaneously form capillary-like tubules on the Matrigel (basement membrane matrix preparation) was photographed under a Nikon Eclipse TE300 phase contrast microscope (Nikon Instruments Inc., Melville, NY, USA) at a magnification of x100.

Detection of VEGF release. MDA-MB-231 cells (60,000 cells/ $\mathrm{cm}^{2}$ ) were grown for $24 \mathrm{~h}$, then washed in PBS and incubated in 


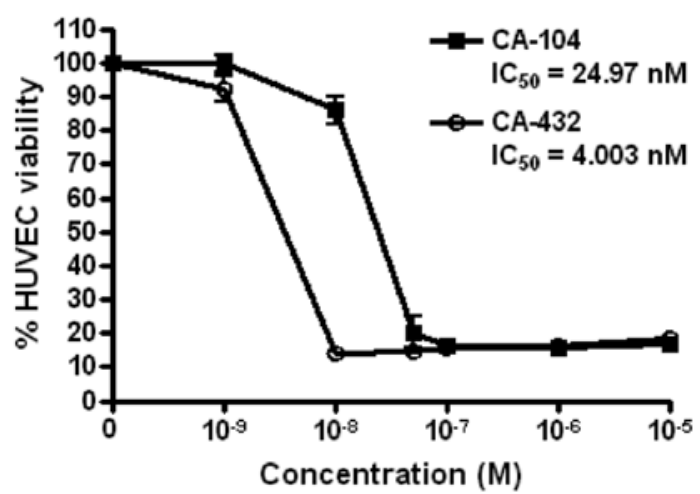

Figure 2. Treatment with cis-restricted $\beta$-lactam combretastatin A-4 analogues, CA-104 and CA-432, reduced viability of primary endothelial cells. HUVECs grown on 96-well plates were treated in triplicate with vehicle alone $[1 \%(\mathrm{v} / \mathrm{v})$ ethanol] or a range of concentrations of CA-104 or CA-432 for $72 \mathrm{~h}$. The cells were then incubated in $10 \%(\mathrm{v} / \mathrm{v})$ AlamarBlue $^{\mathrm{TM}}$ and its reduction to a fluorescent state was measured at excitation $544 \mathrm{~nm}$ and emission $590 \mathrm{~nm}$ using a multi-well fluorimeter. The results were expressed as the percentage of cell viability relative to vehicle-treated control cells $(100 \%)$. Values represent the mean \pm SEM for three separate experiments. $\mathrm{IC}_{50}$ values (concentration of the compound resulting in 50\% reduction in cell viability) were obtained using Prism GraphPad 4 software.

a low serum environment [DMEM supplemented with $1 \%(\mathrm{v} / \mathrm{v})$ FBS] in the presence or absence of lead analogue CA-432 for $6 \mathrm{~h}$. The conditioned medium was then centrifuged at $400 \mathrm{xg}$ and the supernatants were collected while the cells were lysed in sample buffer [62.5 mM Tris ( $\mathrm{pH}$ 6.8), $2 \%$ (w/v) SDS, $10 \%$ (v/v) glycerol], sonicated briefly and denatured by boiling for $3 \mathrm{~min}$. The concentration of VEGF in the supernatants was determined by ELISA using a Quantikine Human VEGF Immunoassay kit (R\&D Systems Inc.) in accordance with manufacturer's handbook. The colour intensity (proportional to the concentration of VEGF) was determined by measuring the absorbance in a SpectraMax 340PC spectrophotometer (Molecular Devices) at wavelength $450 \mathrm{~nm}$ with correction at $540 \mathrm{~nm}$. The readings were normalised to account for the total protein content of the cells which was determined from an aliquot of cell lysate using a BCA protein assay kit (Pierce, Thermo Fisher Scientific Inc., Rockford, IL, USA) in accordance with the manufacturer's instructions. Normalised VEGF-release was then expressed as a percentage of release from vehicle-treated control cells (100\%).

Tumour cell migration. MDA-MB-231 cells were seeded at a density of 25,000 cells/well onto 24-well Falcon migration inserts ( $8-\mu \mathrm{m}$ pore size) (BD Biosciences) in serum-free medium. Inserts were placed into Falcon companion plates containing DMEM supplemented with $20 \%$ FBS in the presence or absence of CA-432. Following $6 \mathrm{~h}$ of incubation, the upper surfaces of the inserts were swabbed to remove non-migrated cells. Migrated cells on the underside of the membrane were fixed in methanol, stained with Mayer's hematoxylin, dehydrated in methanol and mounted on a glass slide. The cells in 5 fields at x10 magnification were counted.

Statistical analysis. Results were presented as mean \pm SEM. Statistical analysis of the experimental data was performed using the computer program Prism GraphPad 4. P-values were determined using a paired two-tailed Student's t-test. A value of $\mathrm{P}<0.05$ was considered to be statistically significant.

\section{Results}

cis-restricted $\beta$-lactam combretastatin A-4 analogues, $C A-104$ and $C A-432$, reduce endothelial cell viability. To determine the effect of $c i$-restricted $\beta$-lactam CA-4 analogues on endothelial cell viability, we tested a range of concentrations of the representative analogues, CA-104 and CA-432, on primary HUVECs for $72 \mathrm{~h}$. We established that both agents led to a reduction in the metabolic activity and hence viability of HUVECs, with respective $\mathrm{IC}_{50}$ values for CA-104 and CA-432 of 24.97 and $4.00 \mathrm{nM}$ (Fig. 2). From these $\mathrm{IC}_{50}$ values, it was deduced that analogue CA-432 was a more potent inhibitor of endothelial cell viability than CA-104. The concentrations of CA-104 and CA-432 used for the rest of this study were chosen to reflect the values obtained from this cell viability assay.

CA-104 and CA-432 induce $G_{2} / M$ arrest and apoptosis in endothelial cells. Cell cycle profiles were examined to define the mechanisms underlying the reduction in endothelial cell viability following exposure to CA-104 and CA-432. HUVECs were treated with vehicle [0.5\% (v/v) ethanol], CA-104 (0.01-1 $\mu \mathrm{M})$ or CA-432 (1-100 nM) for $24 \mathrm{~h}$. Subsequently, their DNA was fluorescently stained with propidium iodide and analysed by flow cytometry. Examination of their DNA profiles indicated that both CA-104 and CA-432 induced a dose-dependent increase in the percentage of HUVECs with 4N DNA content compared to vehicle-treated cells. Approximately $20 \%$ of HUVECs treated with the vehicle alone displayed tetraploid DNA contents compared to $38.1 \pm 1.5 \%$ $(\mathrm{P}=0.0063)$ or $37.0 \pm 1.8 \%(\mathrm{P}=0.0027)$ of the HUVECs treated with CA-104 (100 nM) or CA-432 (50 nM) respectively (Fig. 3A and B). These statistically significant increases in $4 \mathrm{~N}$ DNA content indicated that the compounds induced arrest in the $G_{2} / M$ phase of the cell cycle.

$\mathrm{G}_{2} / \mathrm{M}$ arrest was accompanied by significant increases in the number of entities presenting with hypodiploid $(<2 \mathrm{~N})$ quantities of DNA as indicated by a sub $\mathrm{G}_{0} / \mathrm{G}_{1}$ peak on the DNA profiles. While only approximately $5 \%$ of vehicletreated HUVECs were found to be hypodiploid, treatment with CA-104 (100 $\mathrm{nM})$ or CA-432 $(50 \mathrm{nM})$ resulted in an increase in the amount of hypodiploid cells to $35.0 \pm 2.6 \%$ $(\mathrm{P}=0.0064)$ or $31.4 \pm 1.3 \%(\mathrm{P}=0.0019)$ respectively (Fig. $3 \mathrm{C}$ and D). These statistically significantly increases in hypodiploid cells represented an increase in the levels of apoptosis. Cell cycle analysis illustrated that both CA-104 and CA-432 inhibited proliferation and survival of endothelial cells through the induction of $\mathrm{G}_{2} / \mathrm{M}$ arrest and apoptosis.

CA-104 and CA-432 cause destabilisation of the microtubule network in endothelial cells. We next established the effect of CA-104 and CA-432 on the gross morphology of the microtubular network in endothelial cells. HUVECs, grown on glass 4-chamber slides, were treated for $16 \mathrm{~h}$ with vehicle [0.5\% (v/v) ethanol], CA-104 (100 nM) or CA-432 (50 nM). Immunofluorescent staining was used to detect morphological changes in the tubulin cytoskeleton such as alterations in 
A

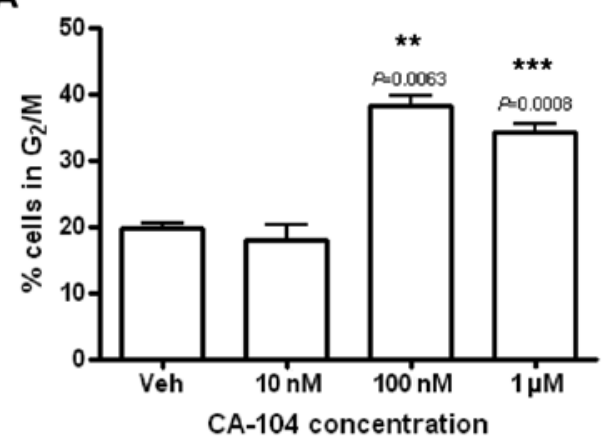

C

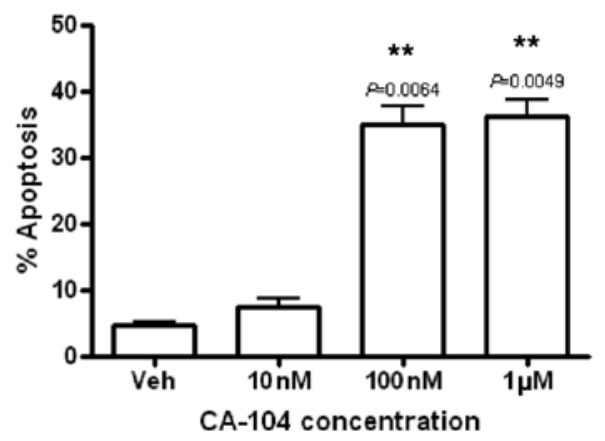

B

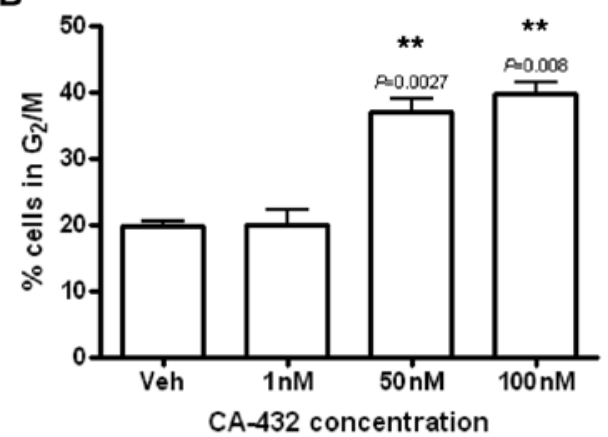

D

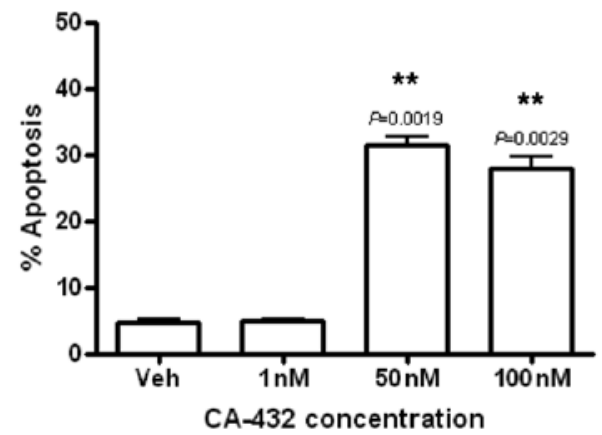

Figure 3. CA-104 and CA-432 induce $\mathrm{G}_{2} / \mathrm{M}$ arrest and apoptosis in primary endothelial cells. HUVECs were treated with vehicle (Veh) [0.5\% (v/v) ethanol] or the indicated concentrations of CA-104 or CA- 432 for $24 \mathrm{~h}$, fixed in ethanol, stained with propidium iodide and their DNA content assessed by flow cytometry. Analysis of data was performed using the CellQuest software. Fluorescence was proportional to the amount of DNA present in each entity and therefore indicated the phase of the cell cycle. Cells in the $\operatorname{subG}_{0} / \mathrm{G}_{1}$ phase $(<2 \mathrm{~N}$ DNA) were deemed apoptotic, while cells with $4 \mathrm{~N}$ quantities of DNA were considered to be in the $\mathrm{G}_{2} / \mathrm{M}$ phase of the cell cycle. Values represent the mean $\pm \mathrm{SEM}$ for three independent experiments. A P-value $<0.05$ was considered to be statically significant $\left({ }^{*} \mathrm{P}<0.05,{ }^{* *} \mathrm{P}<0.01,{ }^{* * *} \mathrm{P}<0.001\right)$.
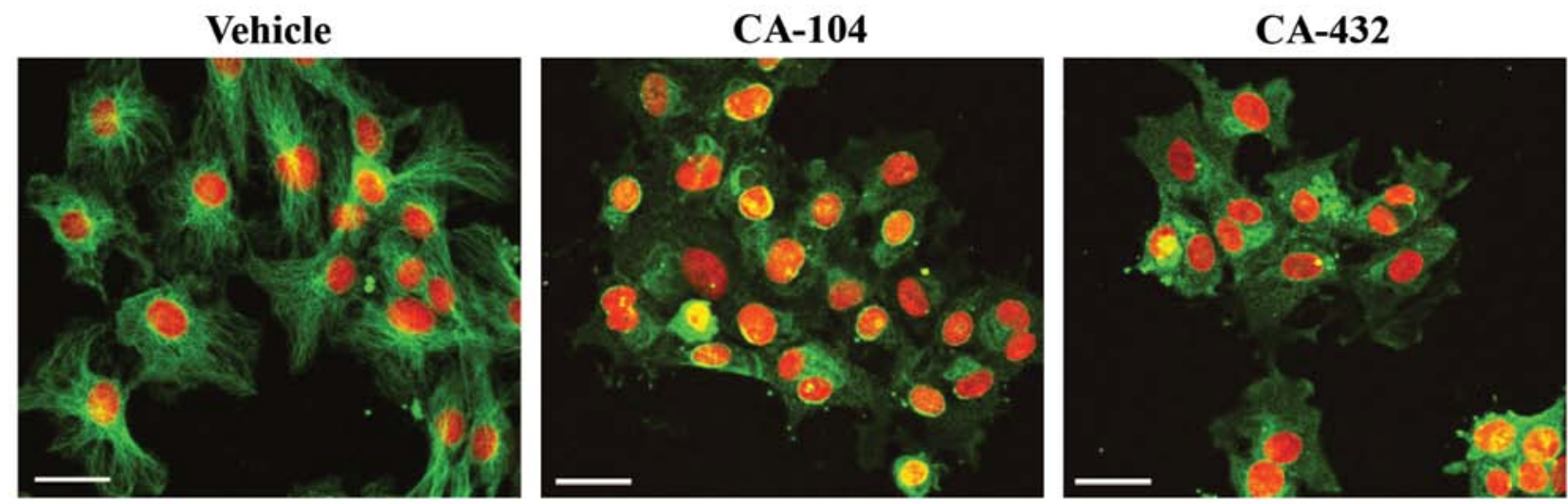

Figure 4. CA-104 and CA-432 disrupt the organisation of the microtubular network in endothelial cells. HUVECs grown on 4-chamber glass slides were treated with vehicle $[0.5 \%(\mathrm{v} / \mathrm{v})$ ethanol], CA-104 $(100 \mathrm{nM})$ or CA-432 $(50 \mathrm{nM})$ for $16 \mathrm{~h}$. The cells were then fixed in methanol, incubated with monoclonal anti$\alpha$-tubulin antibodies, followed by FITC-conjugated anti-mouse antibodies and then briefly stained with propidium iodide. The organisation of the microtubule network (green) and the cellular DNA (red) was visualised using a fluorescence microscope at a magnification of x600 (scale bar, $30 \mu \mathrm{m}$ ). Images illustrated are representative of three independent experiments.

organisation and arrangement. In normal cells, the microtubule network is organised into cytoplasmic tubulin filaments radiating from a central point to the periphery. HUVECs treated with vehicle alone $(0.5 \%$ ethanol) displayed this typical tubulin morphology (Fig. 4). Treatment of cells with tubulin polymerising agents (for example, paclitaxel) results in a highly concentrated accumulation of filaments into dense peripheral bundles indicative of microtubule stabilisation. In contrast, exposure of cells to tubulin depolymerising agents (such as vincristine) results in diffuse tubule staining with no definition of structure caused by microtubule disassembly. These typical morphological changes associated with tubulin depolymerising agents were observed when HUVECs were treated with either CA-104 or CA-432 (Fig. 4). 


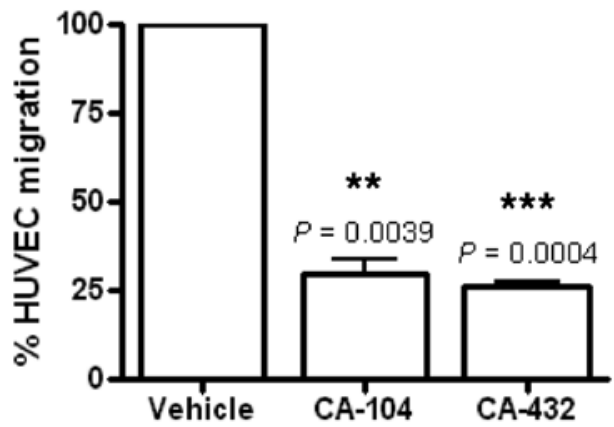

Figure 5. CA-104 and CA-432 significantly reduce VEGF-stimulated endothelial cell migration. HUVECs were seeded onto fibronectin-coated Transwell inserts and placed in medium-containing companion plates. HUVEC migration was stimulated by the addition of $10 \mathrm{ng} / \mathrm{ml}$ VEGF to the lower well in the presence of vehicle $[0.5 \%(\mathrm{v} / \mathrm{v})$ ethanol], CA-104 $(100 \mathrm{nM})$ or CA-432 $(50 \mathrm{nM})$. After $6 \mathrm{~h}$, migrated cells were stained with $0.5 \%$ toulidine blue $\mathrm{O}$ and $0.5 \%$ sodium tetraborate and quantified as absorbance at $650 \mathrm{~nm}$ The results were expressed as the percentage of migrated cells with vehicletreated control cells representing $100 \%$ migration and displayed as mean \pm SEM of three experiments each carried out in duplicate. A P-value $<0.05$ was considered to be statically significant $\left({ }^{*} \mathrm{P}<0.05,{ }^{* * *} \mathrm{P}<0.01,{ }^{, * * *} \mathrm{P}<0.001\right)$.

CA-104 and CA-432 reduce endothelial cell migration. Having established that $c i s$-restricted $\beta$-lactam combretastatin A-4 derivatives altered endothelial cell function, we then examined their implications in angiogenic processes in vitro. Firstly, their effect on HUVEC migration was evaluated using a modified Transwell migration assay. This chemotactic model representative of tumour-induced endothelial cell migration (23) consisted of an upper and a lower chamber separated by a membrane. Migration of HUVECs from the upper to the lower chamber was stimulated by the addition of VEGF to the lower chamber. The effect of CA-104 (100 nM) and CA-432 (50 nM) on this migration was determined by their addition along with VEGF into the lower chamber. Migration was expressed as a percentage of migration by vehicle-treated cells (100\%). Incubation for $6 \mathrm{~h}$ with CA-104 or CA-432 significantly inhibited VEGF-stimulated HUVEC migration by $70.3 \pm 4.4 \%$ $(\mathrm{P}=0.0039)$ and $74.0 \pm 1.5 \%(\mathrm{P}=0.0004)$ respectively (Fig. 5). This effect preceded endothelial cell toxicity since no loss of HUVEC viability was evident following a 6-h treatment with CA-104 or CA-432 (data not shown).
CA-104 and CA-432 inhibit endothelial cell differentiation. To further investigate the anti-angiogenic potential of CA-104 and CA-432, an endothelial tube formation assay was performed. The spontaneous formation of capillary-like structures by endothelial cells, when incubated on an extracellular basement membrane matrix preparation known as Matrigel, is a standard in vitro angiogenesis test (24). This process requires cell-matrix interaction, inter-cellular communication as well as cell motility and differentiation. HUVECs were seeded onto Matrigel in the presence of vehicle ( $0.5 \%$ ethanol), CA-104 (100 nM) or CA-432 (50 nM) for $6 \mathrm{~h}$. The alignment of the cells on the 3D-Matrigel was assessed using a phase contrast microscope (Fig. 6). Vehicle-treated cells underwent alignment into capillary-like structures while treatment with either CA-104 or CA-432 reduced tubule formation. Again, as observed during the endothelial cell migration assay, inhibition of in vitro tubule formation preceded any cytotoxic effects attributed to CA-104 or CA-432.

CA-432 reduces VEGF release from breast carcinoma cells. The release of VEGF from tumour cells plays a key role in the stimulation of angiogenesis and promotion of endothelial cell survival (25). Therefore, we next investigated the effect of lead CA-4 analogue CA-432 (50 nM) on the release of VEGF from human breast adenocarcinoma MDA-MB-231 cells. VEGF release was stimulated by incubating the cells in a low serum environment. We found that the CA-432 $(50 \mathrm{nM})$ reduced the release of VEGF from MDA-MB-231 cells to $80.9 \pm 1.7 \%$ $(\mathrm{P}=0.0080)$ of that released from the vehicle-treated control cells (Fig. 7). This event preceded any cytotoxic effects due to CA-432, since at $6 \mathrm{~h}$ post-treatment, no loss in MDA-MB231 cell viability was detected (data not shown). This finding suggested an indirect anti-angiogenic function for CA-432 through targeting of tumour cells.

CA-432 prevents migration of breast carcinoma MDA-MB231 cells. The migration of tumour cells from the primary site is a critical step during tumour metastasis (26). We previously demonstrated that MDA-MB-231 cells display good migratory capabilities (27). Therefore, the migration of MDA-MB-231 cells across Transwell filters in the presence of vehicle [0.5\% (v/v) ethanol] or CA-432 (50 nM) was compared. Migration was expressed as a percentage of the migration of vehicle-
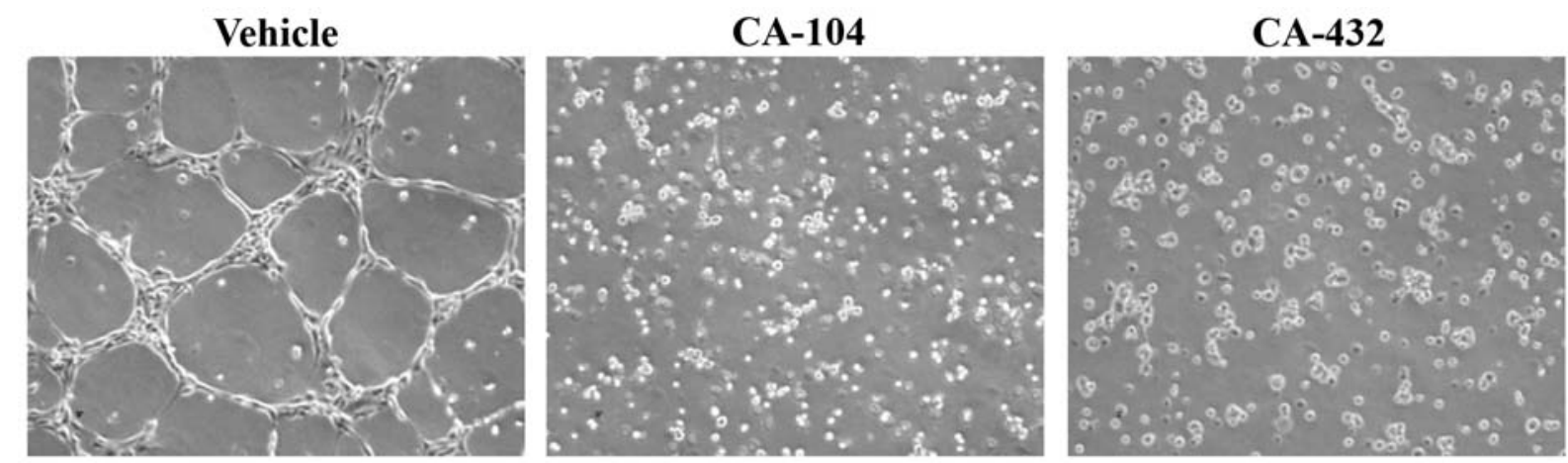

Figure 6. CA-104 and CA-432 inhibit the spontaneous in vitro tubule formation of endothelial cells. HUVECs were grown on Matrigel-coated 6-well plates for $6 \mathrm{~h}$ in the presence of vehicle [0.5\% (v/v) ethanol], CA-104 (100 nM) or CA-432 (50 nM). The ability of the HUVECs to form capillary-like tubules on Matrigel was demonstrated using a phase contrast microscope at a total magnification of x100. Images shown are representative of three independent experiments. 


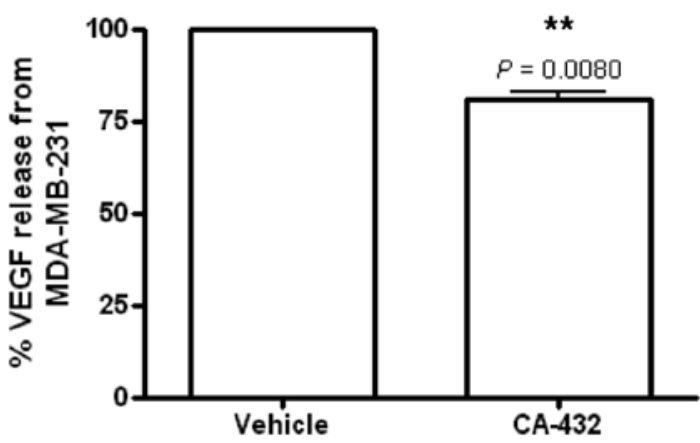

Figure 7. CA-432 reduces VEGF-release from human breast adenocarcinoma MDA-MB-231 cells. MDA-MB-231 cells were treated with vehicle [0.5\% (v/v) ethanol] or CA-432 $(50 \mathrm{nM})$ for $6 \mathrm{~h}$ in a low serum environment [DMEM supplemented with $1 \%(\mathrm{v} / \mathrm{v})$ FBS]. The conditioned medium was then centrifuged at $400 \mathrm{x} \mathrm{g}$ and the supernatants were collected. The concentration of VEGF in the supernatants was determined by ELISA. The results were normalised for cellular protein concentration and expressed as the percentage of VEGF released in the CA-432-treated cells compared to release from vehicle-treated control cells $(100 \%)$. Data represents the mean \pm SEM of three experiments each carried out in duplicate. A value of $\mathrm{P}<0.05$ was considered to be statistically significant $\left({ }^{*} \mathrm{P}<0.05,{ }^{* *} \mathrm{P}<0.01,{ }^{* * *} \mathrm{P}<0.001\right)$.

treated cells (100\%). Incubation for $6 \mathrm{~h}$ with $\mathrm{CA}-432$ prevented MDA-MB-231 cell migration by $95.7 \pm 0.7 \%(\mathrm{P}<0.0001)$ (Fig. 8). This event preceded any cytotoxic events, since following a $6 \mathrm{~h}$ treatment with CA-432, no loss in MDA-MB231 cell viability was detected (data not shown).

\section{Discussion}

Both tumour vascularisation and the migration of tumour cells are key events during the growth and metastatic progression of tumours. Therefore, agents that disrupt these events could potentially prove useful as anti-cancer therapies. Anti-vascular therapies can be divided into two main strategic subtypes: vascular-disrupting therapies that target the existing tumour vasculature and anti-angiogenic therapies that prevent the de novo synthesis of tumour blood vessels. CA-4 and its water soluble prodrug CA-4P fall into the first category (7) while microtubule-targeting agents such as the tubulin-stabilising taxanes (28) and the tubulin-destabilising vinca alkaloids (29) form the latter group. However, between these two subtypes there are overlaps, as depending on the dosing strategies, antiangiogenic agents can also induce vascular disruption and the converse is also true (30). Therefore, the in vitro assays used to detect both strategies are similar. Anti-vascular therapies maximise their effects on the tumour vasculature while minimising damage to the systemic vasculature system by exploiting the fundamental differences between the normal mature vasculature and the immature tumour vasculature which tends to be disorganised, leaky and poorly associated with perivascular cells (31).

Endothelial cells are desirable targets for cancer therapies due to accessibility and genetic stability and unlike tumour cells, they do not readily acquire drug resistance (32). Hence, anti-vascular drugs can cause tumour regression even in drug-resistant tumours. For example, anti-tumour activity was reported with docetaxel in a xenograft tumour that had been established by inoculating mice with docetaxel-resistant

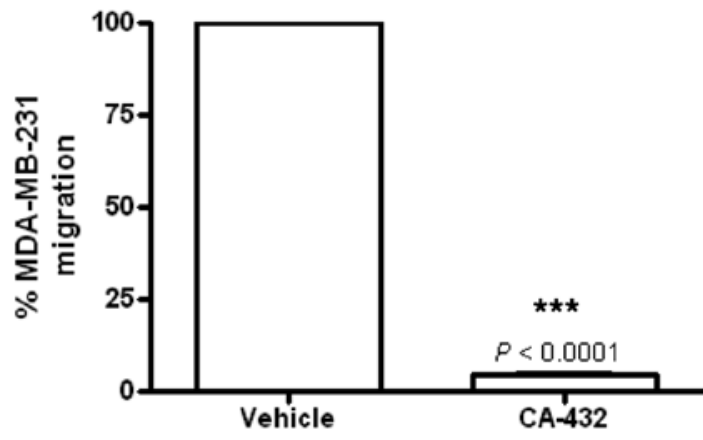

Figure 8. CA-432 inhibits the migration of human breast adenocarcinoma MDA-MB-231 cells. MDA-MB-231 cells were seeded onto Transwell inserts in serum-free medium and placed into companion plates containing $20 \%$ (v/v) FBS/DMEM and either vehicle [0.5\% (v/v) ethanol] or CA-432 (50 nM) for $6 \mathrm{~h}$. The upper surfaces of the inserts were swabbed to remove nonmigrated cells. Migrated cells on the underside of the membrane were fixed in methanol, stained with Mayer's hematoxylin, dehydrated in methanol and mounted on a glass slide. The number of cells in 5 fields at x 10 magnification was counted. The results were expressed as the percentage of migrated cells relative to vehicle-treated control cells $(100 \%)$ and represent the mean \pm SEM of three independent experiments. A value of $\mathrm{P}<0.05$ was considered to be statistically significant $\left({ }^{*} \mathrm{P}<0.05,{ }^{* *} \mathrm{P}<0.01,{ }^{* * *} \mathrm{P}<0.001\right)$.

cancer cells, an effect that was attributed to the anti-angiogenic actions of docetaxel (33). After tumour vascularisation, several key events are critical for progression of a tumour to a metastatic phenotype. These events include migration of tumour cells from the primary site into the blood/lymph system followed by their invasion into a different site to begin the process of angiogenesis and the growth of a secondary tumour (26). Therefore, agents which target either the tumour vasculature or any of the steps that occur during tumour metastasis are potentially useful anticancer therapies, with agents that target both events the most desirable.

Naturally occurring stilbene, CA-4, is a potent inhibitor of tubulin polymerisation that displays potent anti-mitotic activities in both cancer and endothelial cells $(2,4,5,7)$. In vivo, its water-soluble prodrug, CA-4P, induces a rapid and selective shutdown of tumour blood flow and subsequently tumour regression $(7,8)$ and thus the compound is currently undergoing clinical trials as a vascular-disrupting agent. The therapeutic efficacy of CA-4 is limited by its intrinsic instability rendering it readily isomerisable to its inactive trans-conformation (15-17). Therefore, non-isomerisable CA-4 analogues have been developed to provide more stable alternatives to CA-4. Approaches to prevent isomerisation have included the replacement of the cis-double bond in CA-4 with heterocyclic rings such as tetrazole, imidazole and benzoxepin (34-36).

We previously developed and patented a series of CA-4 analogues that are conformationally cis-restricted. Replacement of the ethylene bridge of CA- 4 with a $\beta$-lactam (2-azetidinone) ring provided a rigid scaffold that prevented cis-trans isomerisation and maintained a similar spatial arrangement between the two phenol rings as the cis-conformation of CA-4 (18). We have already established that some of these compounds displayed potent anti-proliferative activity in several cancer cell lines and ex vivo patient samples, including those displaying multidrug resistance (18-21). However, the anti-vascular and anti-metastatic properties of these cisrestricted analogues remained to be elucidated. The purpose 
of this study was to perform a series of in vitro experiments to investigate the anti-vascular effects of the compounds directly on primary HUVECs and indirectly on the release of proangiogenic VEGF from tumour cells. Finally, we assessed the effect of the analogues on one of the critical events involved in metastasis, namely, tumour cell migration.

We selected two of the lead cis-restricted CA-4 analogues from our previous studies as representative compounds, CA-104 and its derivative CA-432, which contained an aryl ring substituent at position $\mathrm{C}-3$ of the $\beta$-lactam ring (Fig. 1). We determined that both analogues potently inhibited HUVEC proliferation with $\mathrm{IC}_{50}$ values of $24.9 \mathrm{nM}$ and $4 \mathrm{nM}$ for CA-104 and CA-432, respectively. These values were either similar or lower than those we previously observed in tumour cells such as breast carcinoma MCF-7 and MDA-MB-231 cells, promyelocytic leukaemia HL60 cells, chronic myeloid leukaemia K562 cells and ovarian carcinoma $\mathrm{A} 2780$ cells, where $\mathrm{IC}_{50}$ values ranged between 17 and $60 \mathrm{nM}$ for CA-104 and 7.5 and $28 \mathrm{nM}$ for CA-432 (18-20). The magnitude of response obtained with CA-432 was similar to those reported for CA-4 and CA-4P which also demonstrated anti-proliferative effects on endothelial cells at lower concentrations than tumour cells $(7,37)$. As we previously reported that exposure of normal breast epithelial cells to CA-432 induced only a minimal amount of cytotoxicity with an $\mathrm{IC}_{50}$ value of greater than $10 \mathrm{mM}(19)$, it is interesting that the compounds had such a potent effect on non-cancerous endothelial cells. This phenomenon has been reported with CA-4P (38) and numerous other microtubuletargeting agents $(22,39)$ and is postulated to be attributable to a variety of mechanisms including enhanced uptake mechanisms in endothelial cells (40) or differences in endothelial cell tubulin composition, its post-translational modifications or its microtubule-associated proteins $(41,42)$.

The loss in endothelial cell viability following exposure to CA-104 and CA-432 was mediated by significant levels of $\mathrm{G}_{2} \mathrm{M}$ arrest and apoptosis which was accompanied by depolymerisation of the microtubular networks in HUVECs. Tubulin depolymerisation and $\mathrm{G}_{2} \mathrm{M}$ arrest are typical responses observed in tumour cells after exposure to the $\beta$-lactam analogues $(19,20)$ and also parallels the effects observed with CA-4/CA-4P in endothelial cells (43). Studies suggest that the type of cell death culminating from CA-4(P)-induced $\mathrm{G}_{2} \mathrm{M}$ arrest varies depending on the conditions and the type of cell. Modes of cytotoxicity reported include apoptosis $(21,44)$, mitotic catastrophe (45) and autophagy $(46,47)$. Recently we found that CA-432 induced mitotic catastrophe in breast carcinoma cells (48) and autophagy in adenocarcinoma-derived colon cancer cells (47). Mitotic arrest prevents the supply of endothelial cells required for angiogenesis and cytotoxicity leads to the destruction of existing tumour blood vessels, indicating a novel anti-vascular function for the $\beta$-lactam CA-4 derivatives.

Apart from the proliferation and survival of endothelial cells, angiogenesis requires several other critical events including the migration of endothelial cells into the extracellular matrix and their differentiation into new capillary networks $(31,49)$. In addition, stimulation of these angiogenic events requires pro-angiogenic or vascular-survival signals such as the release of VEGF by tumour cells (50). Interference in these processes has been reported in endothelial and tumour cells treated with MTAs such as paclitaxel, docetaxel, vinblastine and vincristine $(28,29,51,52)$. We established that $\beta$-lactam CA-4 analogues were capable of directly interfering with angiogenic events since they completely abrogated VEGF-stimulated HUVEC migration and their spontaneous differentiation into capillary-like structures when grown on Matrigel, both standard tests for angiogenesis in vitro. Furthermore, the derivatives may also indirectly influence angiogenesis, as CA-432 significantly reduced the release of VEGF from metastatic breast carcinoma MDA-MB-231 cells by almost $20 \%$. This is an interesting effect as in addition to its angiogenic activity, VEGF can protect endothelial cells from apoptosis by stimulating the activation of survival pathways such as phosphoinositol-3-kinase (PI3 kinase) and upregulation of anti-apoptotic Bcl-2 and in particular survivin which is an important microtubule-binding apoptosis inhibitor involved in mitotic spindle regulation (53-56).

These anti-angiogenic findings provided additional support to the anti-vascular profile of these CA-4 derivatives and it is interesting to note that these anti-angiogenic responses occurred at time points that preceded the onset of cytoxicity indicating that the anti-vascular phenotype of these compounds cannot solely be attributed to endothelial cell death. This effect was also observed with CA-4P which can induce complete vascular shutdown within 20 min of drug exposure in vivo (57). As drug-induced effects on endothelial cell proliferation or cytotoxicity occur too slowly to account for this rapid response, it has been postulated that morphological and functional changes in endothelial cells are more likely to cause tumour vascular collapse $(30,58)$. Such changes may include rounding-up of cells due to disruption of interphase microtubules leading to rapid remodelling of the actin cytoskeleton, assembly of actin stress fibres, actinomyosin contractility, formation of focal adhesions, disruption of cellcell junctions, including those involving $\mathrm{N}$ - and VE-cadherin and an increase in monolayer permeability of macromolecules $(14,59,60)$. It would therefore, be interesting in the future to investigate some of these mechanisms to extend our study of the $\beta$-lactam CA- 4 analogues. It is important to note that our initial observations which illustrated inhibition of endothelial cell proliferation and cytotoxicity are still important therapeutically, since these mechanisms can play a role in the prevention of tumour re-growth in chronic dosing schedules.

Finally, we investigated the effect of CA-432 on one of the key events that occurs during metastasis, tumour cell migration. We chose breast adenocarcinoma MDA-MB-231 cells as a model since we previously found that these cells displayed good migratory potential (27). We determined that CA-432 abrogated MDA-MB-231 migration from a low to a high serum environment. We previously showed that CA-432 has an $\mathrm{IC}_{50}$ value of $28.8 \pm 0.02 \mathrm{nM}$ in these cells (19), however, similarly to endothelial cell migration, interference with tumour cell migration preceded cytotoxicity.

In summary, these findings demonstrated novel antivascular and anti-metastatic functions for our cis-restricted $\beta$-lactam combretastatin A-4 analogues, CA-104 and CA-432. Collectively, this report along with our previous studies indicate that these $\beta$-lactam CA-4 analogues induced anti-tumour, anti-vascular and anti-metastatic events with minimal toxicity to normal quiescent cells in vitro. These events are analogous 
with the functions of CA-4 in vitro. Therefore, these analogues should now be considered for further in vivo investigation of their anti-tumour and anti-vascular capabilities to further evaluate their potential as useful alternatives to the intrinsically unstable CA-4.

\section{Acknowledgements}

This study was kindly funded by the Health Research Board Ireland (Grant RP/2007/42). We acknowledge the assistance of the technical staff of the School of Biochemistry and Immunology, Biomedical Sciences Institute, Trinity College Dublin, Ireland, in particular, Dr Orla Hanrahan and Dr Gavin McManus of the Microscopy and Imaging Facility and Mr. Barry Moran of the Flow Cytometry Facility.

\section{References}

1. Pettit GR, Singh SB, Niven ML, Hamel E and Schmidt JM: Isolation, structure, and synthesis of combretastatins A-1 and B-1, potent new inhibitors of microtubule assembly, derived from Combretum caffrum. J Nat Prod 50: 119-131, 1987.

2. Lin CM, Singh SB, Chu PS, Dempcy RO, Schmidt JM, Pettit GR and Hamel E: Interactions of tubulin with potent natural and synthetic analogs of the antimitotic agent combretastatin: a structure-activity study. Mol Pharmacol 34: 200-208, 1988

3. Mollinedo F and Gajate C: Microtubules, microtubule-interfering agents and apoptosis. Apoptosis 8: 413-450, 2003.

4. Pettit GR, Singh SB, Hamel E, Lin CM, Alberts DS and GarciaKendall D: Isolation and structure of the strong cell growth and tubulin inhibitor combretastatin A-4. Experientia 45: 209-211, 1989.

5. Nabha SM, Wall NR, Mohammad RM, Pettit GR and Al-Katib AM: Effects of combretastatin A-4 prodrug against a panel of malignant human B-lymphoid cell lines. Anticancer Drugs 11: 385-392, 2000.

6. Pettit GR, Temple C Jr, Narayanan VL, Varma R, Simpson MJ, Boyd MR, Rener GA and Bansal N: Antineoplastic agents 322. Synthesis of combretastatin A-4 prodrugs. Anticancer Drug Des 10: 299-309, 1995.

7. Dark GG, Hill SA, Prise VE, Tozer GM, Pettit GR and Chaplin DJ: Combretastatin A-4, an agent that displays potent and selective toxicity toward tumor vasculature. Cancer Res 57: 1829-1834, 1997.

8. Grosios K, Holwell SE, McGown AT, Pettit GR and Bibby MC: In vivo and in vitro evaluation of combretastatin A-4 and its sodium phosphate prodrug. Br J Cancer 81: 1318-1327, 1999.

9. Rustin GJ, Galbraith SM, Anderson H, Stratford M, Folkes LK, Sena L, Gumbrell L and Price PM: Phase I clinical trial of weekly combretastatin A4 phosphate: clinical and pharmacokinetic results. J Clin Oncol 21: 2815-2822, 2003.

10. Nathan P, Zweifel M, Padhani AR, Koh DM, Ng M, Collins DJ, Harris A, Carden C, Smythe J, Fisher N, Taylor NJ, Stirling JJ, Lu SP, Leach MO, Rustin GJ and Judson I: Phase I trial of combretastatin A4 phosphate (CA4P) in combination with bevacizumab in patients with advanced cancer. Clin Cancer Res 18: 3428-3439, 2012.

11. Mooney CJ, Nagaiah G, Fu P, Wasman JK, Cooney MM, Savvides PS, Bokar JA, Dowlati A, Wang D, Agarwala SS, Flick SM, Hartman PH, Ortiz JD, Lavertu PN and Remick SC: A phase II trial of fosbretabulin in advanced anaplastic thyroid carcinoma and correlation of baseline serum-soluble intracellular adhesion molecule-1 with outcome. Thyroid 19 233-240, 2009.

12. A service of the U.S. National Institutes of Health: www. clinicaltrials.gov. Accessed September 14, 2012.

13. Galbraith SM, Chaplin DJ, Lee F, Stratford MR, Locke RJ, Vojnovic B and Tozer GM: Effects of combretastatin A4 phosphate on endothelial cell morphology in vitro and relationship to tumour vascular targeting activity in vivo. Anticancer Res 21: 93-102, 2001.

14. Kanthou $\mathrm{C}$ and Tozer GM: The tumor vascular targeting agent combretastatin A-4-phosphate induces reorganization of the actin cytoskeleton and early membrane blebbing in human endothelial cells. Blood 99: 2060-2069, 2002.
15. Pettit GR, Rhodes MR, Herald DL, Hamel E, Schmidt JM and Pettit RK: Antineoplastic agents. 445. Synthesis and evaluation of structural modifications of (Z)- and (E)-combretastatin A-41. J Med Chem 48: 4087-4099, 2005.

16. Woods JA, Hadfield JA, Pettit GR, Fox BW and McGown AT: The interaction with tubulin of a series of stilbenes based on combretastatin A-4. Br J Cancer 71: 705-711, 1995.

17. McGown AT and Fox BW: Structural and biochemical comparison of the anti-mitotic agents colchicine, combretastatin A4 and amphethinile. Anticancer Drug Des 3: 249-254, 1989.

18. Carr M, Greene LM, Knox AJ, Lloyd DG, Zisterer DM and Meegan MJ: Lead identification of conformationally restricted $\beta$-lactam type combretastatin analogues: synthesis, antiproliferative activity and tubulin targeting effects. Eur J Med Chem 45: 5752-5766, 2010.

19. O'Boyle NM, Carr M, Greene LM, Bergin O, Nathwani SM, McCabe T, Lloyd DG, Zisterer DM and Meegan MJ: Synthesis and evaluation of azetidinone analogues of combretastatin A-4 as tubulin targeting agents. J Med Chem 53: 8569-8584, 2010.

20. Greene LM, Nathwani SM, Bright SA, Fayne D, Croke A, Gagliardi M, McElligott AM, O'Connor L, Carr M, Keely NO, O'Boyle NM, Carroll P, Sarkadi B, Conneally E, Lloyd DG, Lawler M, Meegan MJ and Zisterer DM: The vascular targeting agent combretastatin-A4 and a novel cis-restricted $\{$ beta\}-lactam analogue, CA-432, induce apoptosis in human chronic myeloid leukemia cells and ex vivo patient samples including those displaying multidrug resistance. J Pharmacol Exp Ther 335: 302-313, 2010

21. Greene LM, Carr M, Keeley NO, Lawler M, Meegan MJ and Zisterer DM: BubR1 is required for the mitotic block induced by combretastatin-A4 and a novel cis-restricted $\beta$-lactam analogue in human cancer cells. Int J Mol Med 27: 715-23, 2011.

22. Nathwani SM, Butler S, Meegan MJ, Campiani G, Lawler M, Williams DC and Zisterer DM: Dual targeting of tumour cells and host endothelial cells by novel microtubule-targeting agents, pyrrolo-1,5-benzoxazepines. Cancer Chemother Pharmacol 65: 289-300, 2010.

23. Auerbach R, Lewis R, Shinners B, Kubai L and Akhtar N: Angiogenesis assays: a critical overview. Clin Chem 49: 32-40, 2003.

24. Kubota Y, Kleinman HK, Martin GR and Lawley TJ: Role of laminin and basement membrane in the morphological differentiation of human endothelial cells into capillary-like structures. J Cell Biol 107: 1589-1598, 1988.

25. Hoeben A, Landuyt B, Highley MS, Wildiers H, Van Oosterom AT and De Bruijn EA: Vascular endothelial growth factor and angiogenesis. Pharmacol Rev 56: 549-580, 2004.

26. Fidler IJ: The pathogenesis of cancer metastasis: the 'seed and soil' hypothesis revisited. Nat Rev Cancer 3: 453-458, 2003.

27. Hughes L, Malone C, Chumsri S, Burger AM and McDonnell S: Characterisation of breast cancer cell lines and establishment of a novel isogenic subclone to study migration, invasion and tumourigenicity. Clin Exp Metastasis 25: 549-557, 2008.

28. Hotchkiss KA, Ashton AW, Mahmood R, Russell RG, Sparano JA and Schwartz EL: Inhibition of endothelial cell function in vitro and angiogenesis in vivo by docetaxel (Taxotere): association with impaired repositioning of the microtubule organizing center. Mol Cancer Ther 1: 1191-1200, 2002.

29. Vacca A, Iurlaro M, Ribatti D, Minischetti M, Nico B, Ria R, Pellegrino A and Dammacco F: Antiangiogenesis is produced by nontoxic doses of vinblastine. Blood 94: 4143-4155, 1999.

30. Tozer GM, Kanthou C, Parkins CS and Hill SA: The biology of the combretastatins as tumour vascular targeting agents. Int J Exp Pathol 83: 21-38, 2002.

31. Pasquier E, Honore S and Braguer D: Microtubule-targeting agents in angiogenesis: where do we stand? Drug Resist Updat 9: 74-86, 2006

32. Kerbel RS: Inhibition of tumour angiogenesis as a strategy to circumvent acquired resistance to anti-cancer therapeutic agents. Bioessays 13: 31-36, 1991

33. Kamat AA, Kim TJ, Landen CN Jr, Lu C, Han LY, Lin YG, Merritt WM, Thaker PH, Gershenson DM, Bischoff FZ, Heymach JV, Jaffe RB, Coleman RL and Sood AK: Metronomic chemotherapy enhances the efficacy of antivascular therapy in ovarian cancer. Cancer Res 67: 281-288, 2007.

34. Ohsumi K, Hatanaka T, Fujita K, Nakagawa R, Fukuda Y, Nihei Y, Suga Y, Morinaga Y, Akiyama Y and Tsuji T: Syntheses and antitumor activity of cis-restricted combretastatins: 5-membered heterocyclic analogues. Bioorg Med Chem Lett 8: 3153-3158, 1998 . 
35. Wang L, Woods KW, Li Q, Barr KJ, McCroskey RW, Hannick SM, Gherke L, Credo RB, Hui YH, Marsh K, Warner R, Lee JY, Zielinski-Mozng N, Frost D, Rosenberg SH and Sham HL: Potent, orally active heterocycle-based combretastatin A-4 analogues: synthesis, structure-activity relationship, pharmacokinetics, and in vivo antitumor activity evaluation. J Med Chem 45: 1697-1711, 2002.

36. Barrett I, Carr M, O'Boyle N, Greene LM, Knox AJ, Lloyd DG, Zisterer DM and Meegan MJ: Lead identification of conformationally restricted benzoxepin type combretastatin analogs: synthesis, antiproliferative activity, and tubulin effects. J Enzyme Inhib Med Chem 25: 180-194, 2010

37. Burns CJ, Fantino E, Powell AK, Shnyder SD, Cooper PA, Nelson S, Christophi C, Malcontenti-Wilson C, Dubljevic V, Harte MF, Joffe M, Phillips ID, Segal D, Wilks AF and Smith GD: The microtubule depolymerizing agent CYT997 causes extensive ablation of tumor vasculature in vivo. J Pharmacol Exp Ther 339: 799-806, 2011

38. Böhle AS, Leuschner I, Kalthoff $\mathrm{H}$ and Henne-Bruns D: Combretastatin A-4 prodrug: a potent inhibitor of malignant hemangioendothelioma cell proliferation. Int J Cancer 87: 838-843, 2000

39. Wang J, Lou P, Lesniewski R and Henkin J: Paclitaxel at ultra low concentrations inhibits angiogenesis without affecting cellular microtubule assembly. Anticancer Drugs 14: 13-19, 2003.

40. Merchan JR, Jayaram DR, Supko JG, He X, Bubley GJ and Sukhatme VP: Increased endothelial uptake of paclitaxel as a potential mechanism for its antiangiogenic effects: potentiation by Cox-2 inhibition. Int J Cancer 113: 490-498, 2005.

41. Pasquier E, Honore S, Pourroy B, Jordan MA, Lehmann M, Briand C and Braguer D: Antiangiogenic concentrations of paclitaxel induce an increase in microtubule dynamics in endothelial cells but not in cancer cells. Cancer Res 65: 2433-2440, 2005.

42. Pourroy B, Honoré S, Pasquier E, Bourgarel-Rey V, Kruczynsk A, Briand $\mathrm{C}$ and Braguer D: Antiangiogenic concentrations of vinflunine increase the interphase microtubule dynamics and decrease the motility of endothelial cells. Cancer Res 66 : 3256-3263, 2006.

43. Kanthou C, Greco O, Stratford A, Cook I, Knight R, Benzakour O and Tozer G: The tubulin-binding agent combretastatin A-4-phosphate arrests endothelial cells in mitosis and induces mitotic cell death. Am J Pathol 165: 1401-1411, 2004.

44. Iyer S, Chaplin DJ, Rosenthal DS, Boulares AH, Li LY and Smulson ME: Induction of apoptosis in proliferating human endothelial cells by tumour-specific antiangiogenesis agent combretastatin A-4. Cancer Res 58: 4510-4514, 1998.

45. Nabha SM, Mohammad RM, Dandashi MH, Coupaye-Gerard B, Aboukameel A, Pettit GR and Al-Katib AM: Combretastatin-A4 prodrug induces mitotic catastrophe in chronic lymphocytic leukemia cell line independent of caspase activation and poly(ADP-ribose) polymerase cleavage. Clin Cancer Res 8 : 2735-2741, 2002

46. Ding X,Zhang Z, Li S and Wang A: Combretastatin A4 phosphate induces programmed cell death in vascular endothelial cells. Oncol Res 19: 303-309, 2011
47. Greene LM, O'Boyle NM, Nolan DP, Meegan MJ and Zisterer DM: The vascular targeting agent combretastatin-A4 directly induces autophagy in adenocarcinoma-derived colon cancer cells. Biochem Pharmacol 84: 612-624, 2012.

48. O'Boyle NM, Carr M, Greene LM, Keely NO, Knox AJ, McCabe T, Lloyd DG, Zisterer DM and Meegan MJ: Synthesis, biochemical and molecular modelling studies of antiproliferative azetidinones causing microtubule disruption and mitotic catastrophe. Eur J Med Chem 46: 4595-4607, 2011.

49. Folkman J: Role of angiogenesis in tumor growth and metastasis. Semin Oncol 29: 15-18, 2002.

50. Conn G, Soderman DD, Schaeffer MT, Wile M, Hatcher VB and Thomas KA: Purification of a glycoprotein vascular endothelial cell mitogen from a rat glioma-derived cell line. Proc Natl Acad Sci USA 87: 1323-1327, 1990.

51. Belotti D, Vergani V, Drudis T, Borsotti P, Pitelli MR, Viale G, Giavazzi R and Taraboletti G: The microtubule-affecting drug paclitaxel has antiangiogenic activity. Clin Cancer Res 2: 1843-1849, 1996

52. Avramis IA, Kwock R and Avramis VI: Taxotere and vincristine inhibit the secretion of the angiogenesis inducing vascular endothelial growth factor (VEGF) by wild-type and drug-resistant human leukemia T-cell lines. Anticancer Res 21: 2281-2286, 2001.

53. Nör JE, Christensen J, Liu J, Peters M, Mooney DJ, Strieter RM and Polverini PJ: Up-regulation of Bcl-2 in microvascular endothelial cells enhances intratumoral angiogenesis and accelerates tumor growth. Cancer Res 61: 2183-2188, 2001.

54. Tran J, Master Z, Yu JL, Rak J, Dumont DJ and Kerbel RS: A role for survivin in chemoresistance of endothelial cells mediated by VEGF. Proc Natl Acad Sci USA 99: 4349-4354, 2002.

55. Li F, Ambrosini G, Chu EY, Plescia J, Tognin S, Marchisio PC and Altieri DC: Control of apoptosis and mitotic spindle checkpoint by survivin. Nature 396: 580-584, 1998.

56. Giodini A, Kallio MJ, Wall NR, Gorbsky GJ, Tognin S, Marchisio PC, Symons M and Altieri DC: Regulation of microtubule stability and mitotic progression by survivin. Cancer Res 62: 2462-2467, 2002.

57. Tozer GM, Prise VE, Wilson J, Cemazar M, Shan S, Dewhirst MW, Barber PR, Vojnovic B and Chaplin DJ: Mechanisms associated with tumor vascular shut-down induced by combretastatin A-4 phosphate: intravital microscopy and measurement of vascular permeability. Cancer Res 61: 6413-6422, 2001.

58. Tozer GM, Kanthou C and Baguley BC: Disrupting tumour blood vessels. Nat Rev Cancer 5: 423-435, 2005.

59. Vincent L, Kermani P, Young LM, Cheng J, Zhang F, Shido K, Lam G, Bompais-Vincent H, Zhu Z, Hicklin DJ, Bohlen P, Chaplin DJ, May C and Rafii S: Combretastatin A4 phosphate induces rapid regression of tumor neovessels and growth through interference with vascular endothelial-cadherin signaling. J Clin Invest 115: 2992-3006, 2005.

60. Tozer GM, Kanthou C, Lewis G, Prise VE, Vojnovic B and Hill SA: Tumour vascular disrupting agents: combating treatment resistance. Br J Radiol 81: S12-S20, 2008. 